\title{
Learning at a virtual campus: Deakin University's experiences as a dual mode university
}

\author{
E. A. Stacey \\ Deakin University \\ 221 Burwood Highway \\ Burwood, Victoria 3125 \\ Australia \\ e-mail:estacey@deakin.edu.au
}

\begin{abstract}
Deakin University was created as a "dual mode" university when the Australian government rejected the single mode model, yet gave Deakin the role of a national distance education provider as well as a regional campus based university. Deakin used the opportunity to become an innovative institution which has used resource based teaching for on and off campus students. Deakin has continued to develop the concept of flexible learning as it has become a multi campus university and has researched and integrated the use of technologies to develop a virtual campus which serves all of its students, both nationally and internationally.
\end{abstract}

Keywords

Dual mode, Flexible learning, Virtual campus, Computer mediated communication, Electronic conferencing 


\section{INTRODUCTION}

\subsection{Deakin's virtual campus}

Paul is based in Kalgoorlie in the Western Australian desert, the third location to which his mining company employer has relocated him during his 2 years studying for a Masters of Business Administration degree. Dave, one of his fellow small group members, is based on the central Queensland coast but frequently works in the remote Northern parts of Australia in his scientific job. Sarah, Melissa and Judy are based in metropolitan cities in South Eastern Australia and a new member of the group, Doug, who is an expatriate Australian working in San Francisco has just joined the group this semester, claiming that this course is still cheaper than most MBA courses he would be eligible to study in America. The group works together on two weekly tutorial assignments to which each person contributes part of the set task. They post their answers to an electronic conference based at Deakin's Burwood campus, for feedback from the group. After the group have discussed the tutorial answers the group assignment is collated - a task shared equally around the group.

The lecturers who coordinate the units that they are studying are based on Deakin's Warrnambool campus on the southern Victorian coast and the tutors who are interacting with the groups and collecting and assessing their group assignments are based on the Burwood (Melbourne metropolitan) campus. The library they access electronically is situated in regional Geelong and the students' administrative support is coming from both Burwood and Geelong.

The physical location of the students is irrelevant, however, as their central communication is through their computers via small and large group electronic conferencing. They access course notes and databases from a related web server and can share and open html documents and URL's of relevant World Wide Web sites as appropriate. Their reading is a mix of print and easily shared and updated electronic documents.

This is Deakin's virtual campus, a meeting point for its students whether they are on or off campus.

\subsection{Deakin's role as a dual mode institution}

Deakin is a dual mode university which was incorporated in 1975 at much the same time as many of the single-mode European institutions. The possibility of a single mode university modelled on the UK Open University at Deakin was ended by the Karmel committee of the Federal government who rejected this type of institution as too centralised and inhibiting to the innovative dual mode approaches already accepted in several Australian universities (Karmel, 1975). There was also a commitment to provide regional universities for our widely scattered remote 
country centres and Deakin was established to provide a regional campus based university at Geelong in country Victoria as well as to be an Australia-wide distance education provider.

The first Vice-Chancellor of Deakin University, Professor Fred Jevons, though inspired by the UK Open University model and wanting to emulate its quality of distance education materials at Deakin, was hindered by the initially small scale of course size at Deakin. The cost factor of producing high quality distance education materials meant that using them with on campus students as well was a feasible way to rationalise costs and Jevons (1986) described this as one of the advantages of the dual mode approach. Other advantages were the greater credibility attached to the courses "if they are seen to come from the same stable as the sort of traditional programs with which people feel comfortably familiar" (Jevons, 1986, p6) as well as the credibility that the research base of the university gave to courses, something which many distance education institutions, at that time, could not provide. Jevons also claimed there were "spillover effects" (p6) of preparing distance education materials which improved the quality of face to face learning and teaching because distance education "brings much of the teaching process out into the open" (p7). Even in Deakin's early days the Vice Chancellor had faith in the convergence theory of technology having the effect of making on and off campus teaching more similar and the distance education institutions more innovative in researching and developing this area.

Deakin has continued to play this role in Australia and to be innovative because of its dual mode role. Though initially driven by a pragmatic rationale as described above, the combination of resource based learning for on and off campus courses has put us at the forefront of the move to flexible learning that has infiltrated the most traditional of our campus based universities with the availability of the technologies of the 1990's. Flexibility of location and circumstance for learning was possible through a student-centred, resource-based approach and Deakin was made University of the Year in 1995, (an award bestowed by external evaluators of the university system, who publish a Good Universities Guide for students (Ashenden \& Milligan, 1995) on the basis of the quality of our flexible and innovative approaches to course design and delivery.

We rationalised our number of faculties to five in the early 1990's as we became a larger multicampus university through nationwide government directed mergers of Universities with Colleges of Advanced Education (Calvert, 1992). All campuses of the new Deakin were encouraged to develop a dual mode of course delivery which produced economies of scale, particularly in some of our larger undergraduate degrees. The continuance of the policy of teaching the same course on and off campus with technological means of delivery and interaction mainstreamed where appropriate and achievable, has meant Deakin has continued to be at the forefront of the convergence of distance and on campus teaching and learning.

Currently at Deakin there are 29,070 students enrolled, 17,102 on campus students enrolled and 11,968 off campus students enrolled. A breakdown of these 
figures show that the on campus full-time student group $(12,462)$ has far greater numbers than the off campus full-time group (1415). Thus the bulk of our offcampus students are part-time, workplace based students, mostly mature age students returning to study for upgrading professional accreditation. The substantial number of our part-time on campus students $(4,640)$ can also benefit from our flexible learning approach by facing less insistence on only face-to-face attendance with a variety of modes of interaction through our virtual campus capabilities. Deakin also has another population of students, as many again as the mainstream university population (approximately 27,650), studying throughout Australia, Europe and Asia through the University's commercial arm, Deakin Australia, and making us one of the largest suppliers of training in Australia.

I will discuss the implementation of our current dual mode approach through a comparative description of several of our university's major course offerings and their modes of delivery. I will provide a commentary gathered from many of the Deakin academic staff involved in teaching and coordinating these courses and will describe their perspectives of dual mode reality and the issues it raises. I will also discuss the way we are planning to explore and implement our progress to a virtual campus (our virtual reality?).

There has been an active and ongoing discussion among distance educators about the continuing directions of single and dual mode universities, particularly as many previously campus based universities have begun to perceive new communication technologies as the means to their global delivery of education. I will conclude with a discussion of some of these issues and our experiences in the context of this discussion, through my own focus as a teacher and researcher at Deakin.

\section{DEAKIN'S COURSE DELIVERY}

\subsection{Overview}

Our dual mode reality in 1997 consists of:

- Undergraduate courses taught in a dual mode with on campus students sharing the same print, multimedia materials and assessment processes as off campus students.

- Many postgraduate courses taught largely off campus with few courses sharing a dual mode of on campus teaching.

- A virtual campus created via computer mediated communication which can transcend an on/off campus division but which is still reaching full implementation.

- Many "off shore" courses, particularly in Asia which use electronic communication within their central course provision.

- University-wide projects aimed at implementing and mainstreaming the capablities of technologies in the delivery and support of all courses at the university, seeking to develop the full market advantage of a dual mode university. 


\subsection{Undergraduate courses}

Many undergraduate courses are still taught to large numbers of students studying full time on campus. We are committed to this process, as the continuing socialisation, as well as education, of the school leaver has long been an important role of the university in our community. As the employment structure of society has changed, this student population has changed too. With fewer immediate prospects of employment when leaving school, competition for tertiary places has increased. Students often work in low skilled jobs at a rate of hours which would have previously been considered full time work loads. Many of them support themselves while studying under a government subsidised delayed fee scheme (students pay a part of their education costs or HECS, the Higher Education Contribution Scheme). Therefore a flexible approach to course teaching also helps these students manage their learning time in less traditional ways.

In some of our major undergraduate courses students have been given the opportunity to use computer laboratories or home computers and modems to link to interactive conferences for some of their tutorials. Ideally these conferences would merge groups of on and off campus students, but though all students on a course are using the same print resources and multimedia resources, difficulties providing stable electronic environments have meant that different approaches have been taken by different faculties and courses in our virtual campus provision.

The Faculty of Business and Law has provided their off campus Bachelor of Commerce students with electronic conferences as an option, rather than a requirement as some of their students had access problems as they attempted to link electronically. There is $40-50 \%$ participation of these off campus students particularly when committed staff have built electronic communication into their course. Currently the on campus students aren't required to use electronic interaction but this is planned for implementation in the next two years as better computer facilities and network provision for on campus students become available.

The Bachelor of Commerce, one of our larger degree courses, has about 1500 students on campus and 500 off campus students who study the same course from the same print guides and the same textbooks. They are assessed in the same way and have the same teaching staff, a dual mode course. The course is also offered in Malaysia with a locally based server enabling electronic communication for course use. The market advantage of such a dual mode is in being able to continue the course in either mode wherever a student may be located. The same resource based course exists in Sydney, Penang, or Western Australia so it can be continued whether a student is moved by their job or for family reasons. The off campus course is well taught and supported often very interactively if electronic conferencing is used. The perception within the market of students and their advisers, of off campus learning being by correspondence only and inferior in interaction and contact, is slowly being changed.

The major undergraduate course of the Faculty of Education, the Education Studies Major, has the opposite situation, with on campus students confident with 
their electronic interaction which is a teaching competency that they are required to develop within their course. The students are able to attend "tutorials" in a flexible electronic environment and discuss issues online each week. However where this would ideally link them to the off campus students, these latter students do not have sufficient access to computers and computer communication to so far make this a viable option. We are attempting new software and electronic access measures to help solve problems but we still have a body of students without computers and modems who we are committed to support. Though all other course material and assessment is the same, the computer based component of the course has had to differ for off campus students until there is equity of electronic access for all students. This means that at present, the on campus students have more modes of interaction and flexibility, with lectures, face-to-face tutorials, print and multimedia resources as well as electronic communication.

Other faculties also teach their undergraduate courses in a parallel mode on and off campus, with off campus students relying more on print and multimedia materials. The Arts Faculty were early innovators who developed materials for on and off campus teaching and have continued teaching a single curriculum. In some more practically oriented courses in the Faculties of Science and Technology and Health and Behavioural Science, face-to-face teaching is seen as more appropriate with 18 year-old school leavers taught on campus. Mature age workplace based students are taught off campus mainly in print mode with some additional computer based delivery.

In the sciences, on campus lectures and classes are still perceived as an integral part of the course, with face-to-face teaching used in teaching the foundational knowledge of maths, physics, biology, building and architecture complemented by practical application. Even in collaborative teaching between Deakin and local institutions in Asia, a face-to- face mode of teaching is supported either by visiting Deakin staff or local lecturers with additional provision of supplementary electronic communication.

However each group is considered in the context of their situation for the most appropriate methods of delivery. Technology is used as a supporting environment, often providing a dialogue for questions and for feedback through news groups and email or electronic conferences. Video teaching between campuses is being trialed in teaching Chemistry and has been used consistently in some cross campus Health Sciences courses. Computer based learning tools are used for enrichment and as replacement for laboratory work for workplace based mature age students. Such technological tools can assist students to link theory with practice, and real world knowledge and can be used with both on and off campus modes, for the students without real world knowledge as well as those in the workplace.

\subsection{Postgraduate courses}

Except for a core of research students, some of whom are campus based, many of Deakin's postgraduate students are studying professional coursework degrees as part time, off campus students. 
Such courses are ideally suited to a virtual campus delivery and this has been established for many of the postgraduate courses

In the Education Faculty, a "virtual graduate school" was begun in 1995 with an electronic conference established using FirstClass conferencing software. Students studying in the Education Doctorate piloted the new system through the use of Deakin Interchange, a suite of software that included FirstClass conferencing and also provided a range of software for accessing the Internet, as well as software tools for research such as database searching tools and bibliographic software.

The Education Doctorate students were not a group who had used computers extensively for communication, as they were mature age students who mainly used computers for word processing. However, as researchers into learning, they expertly articulated the process of learning to use the online environment and provided us with a rich source of data for understanding the development of an active online discussion and the processes it involved (Stacey, 1997b). Providing these students with a virtual space for discussion of their research, as well as methodology and content issues, has broken down the isolation that many off and on campus research students experience.

The electronic conference has become the main form of communication for the Education Doctorate and with a course requirement to gain electronic access, its use has been mainstreamed which has facilitated an active and essential discussion. Electronic communication use has been built into the course structure with tasks which require students to share written contributions for discussion within small groups. The required electronic communication use and the required integrated tasks are factors which have made the virtual discussion central to the doctoral program. With a committed course team as well as provision for technical and student support in the developmental stages, it has become a valuable virtual campus where students generously share experiences, ideas and information and challenge each others ideas. It has also been possible to set up specialised discussions with guest lecturers from other countries which provides our students with access to experts. This process has a flexibility that means students communicate as a group though they are living in distant locations from New Zealand to Western Australia to Asia.

Students in the Masters of Distance Education course, who had been early electronic communication pioneers at Deakin with an older textbased system, also upgraded to the more user friendly graphical interface of First Class to become part of the virtual graduate school. Students studying the theory and issues of distance education have become active conferencers through coursework that has used an electronic discussion of ongoing tasks and activities to engage students in learning interactively. Conferences are gradually being integrated into course delivery of all the faculty's masters coursework programs as staff become confident of teaching this way and begin to embed the use of CMC into their coursework. There is a need for staff commitment and active use of the electronic conferences to guarantee their success. Ongoing response and facilitation of group interaction by the teacher is an important aspect of CMC use. 
A unit focusing on teaching and learning with CMC has also been included in the newly accredited Master of Professional Education and Training in the Faculty of Education in response to students' growing interest in the theory and practice of teaching in a virtual medium. The research study from which this unit was developed was one which researched another electronically pioneering course at Deakin, the Master of Business Administration course.

The Faculty of Business and Law has been committed to providing innovative course delivery for their MBA course from its beginnings as the first such course available by distance education in Australia. There is a syndicate group structure which is central to the pedagogy of the course, with students studying and collaborating together in small groups of up to ten students, simulating, a workplace team environment. As students are situated remotely from one another, this grouping process required a central electronic communication system as a way that students could share documents and discuss issues.

From researching the practice of innovative teaching staff within the course, I found that $\mathrm{CMC}$ was used effectively when lecturers were able to structure an authentic use for interaction and when the electronic conference was central to the course activity with conference contributions counting towards assessment. The MBA's small groups were also a way of managing electronic conferencing effectively when there were large student numbers who would be an unwieldy and overwhelming large group discussion. By learning collaboratively through structured tasks, students shared the diverse perspecti res of the group members, clarified ideas through the group communication and gained feedback to ideas from group members. They could seek group solutions for problems and share resources and provide a supportive social environment for ongoing study (Stacey, 1997a).

The MBA has provided electronic communication for up to 400 students concurrently with the greatest effectiveness in subjects that have built the conference interaction into the assessable tasks and expectations of the subject delivery. Staff commitment to this communication is essential for its successful use especially as the student group use of CMC is the course's main focus.

A new Master of Commerce course offered by this faculty has also made a commitment to the use of electronic interactive groups. As a new full fee paying course directed to the workplace based students, a computer and modem and Internet access are required and the course is being marketed as providing electronic access and interaction. From the beginning of the course, staff are being involved in professional development through an especially established electronic conference and course and there is an executive commitment for staff to teach in an active electronic campus.

\subsection{Deakin's Virtual Campus}

One of the major barriers to the successful mainstreaming of the virtual campus has been the cultural change required to get staff to become confident online 
teachers. Many staff have been used to traditional distance education where little interaction with students was required, the main interaction for the student being with the well prepared text for the course. There were often minimal phone calls to students and cost cutting anonymous markers used as ways of reducing costs of courses. The legacy of such a system meant that some staff became comfortable teaching like this and in an environment which rewards research and publication, these could be more easily achieved without the time consuming teaching that electronic conferencing can mean. The professional development required to develop confidence to teach successfully in a virtual mode was often rushed or put off with the ever increasing busy workload of academic staff.

The distance education literature is divided about the issue of changing this focus and direction of distance teaching, particularly with Holmberg's (1989) theoretical support of the notion of the autonomous student interacting with effective text and individualised tutor feedback. Bates (1991) argues that this focus on the importance of interaction to distance education is a function of the involvement of dual mode universities particularly that of Australia and North America (Bates, 1995) and the value they place on traditional interactive on-campus teaching. However the research (Stacey, 1997a) and evaluation (Goodwin et al, 1995) carried out at Deakin has developed a theoretical basis for the value of an interactive virtual campus which uses collaborative group learning to improve the effectiveness of distance learning.

The student and market demand for a virtual campus has also driven Deakin's strategic planning to make this a mainstream possibility. To address the need for staff to become more capable of teaching in such a virtual campus environment, Deakin has recently launched a new range of projects to mainstream flexible learning through electronic delivery of courses. This is in response to the worldwide changes that have occurred in electronic communication and the expectation of students that digital technologies are used in teaching and learning. Deakin's strategic plan defines Deakin's need "to provide learning experiences which are flexible; accessible; technologically advanced; learner centred and customer focused; service oriented; and which recognise the needs of lifelong learners." (Rowlands, 1997, p1) has focused activity at Deakin to provide professional development and support for staff learning to teach electronically.

Deakin's dual mode approach will be enhanced by the capability of a more efficient provision of interactive communications technologies and by developing the capability of staff to teach with theses technologies. The support services in the university, Information Technology Services, Learning Resource Services (print, editorial and graphical design), Academic Development (including software development and professional support) and the Library are all being integrated into the project so that academic staff have time release and access to skilled staff as they develop their courses into appropriate technological media.

Such a strongly coordinated project with active executive involvement and support will be worth watching as it unfolds at Deakin. Strong leadership combined with the involvement of innovative staff, cooperative effort from all branches of the university's support services and resources and efforts pitched at 
the mainstream course delivery level should take Deakin's dual mode strengths into a virtual campus that combines to better serve the needs of all students.

The virtual campus has the potential to change the dual mode process significantly as groups of students can be taught as one group regardless of their physical location. This possibility is also attractive to the traditional campus based universities who have begun to look at technology as a means of providing them with a global market and could change the process of distance education provision worldwide. In Australia achieving this reality has been a slower process than originally conceived (Hesketh et al, 1996), particularly as our technological infrastructure has only recently been developed to reach many of the locations of the student population who require electronic access. Just as important have been the development of student and staff computer capabilities and skills which are only slowly reaching a point where they make use of a virtual classroom. Only as access is improved and as the teachers' skills in the electronic environment are developed, can there be a true merging of on and off campus student groups.

The virtual campus is very much dependent on the abilities and commitment of its community to interact in this mode. As Daniel (1997) has commented, the virtual university will fail "unless it can evoke the personal commitment from students and staff that is the basis of an academic community." Deakin is seeking through its current projects to translate the current commitment to the dual mode approach into the new technological environments so that its virtual campus can provide a more effective learning environment for all its students.

\section{REFERENCES}

Ashenden, D., \& Milligan, S. (1995). Good universities guide to Australian universities and other higher institutions. Port Melbourne: Mandarin Australia.

Bates, A. W. (1991). Third generation distance education: The challenge of new technology. Research in Distance Education 3 3(2), 10-14.

Bates, A. W. (1995). Technology, open learning and distance education. London: Routledge.

Calvert, J. (1992). Deakin University. In Mugridge, I. (Ed.), Perspectives on distance education: distance education in single and dual mode universities. (pp. 19-31). Vancouver: Commonwealth of Learning.

Daniel, J. (1997). The mega-university: The academy for the new millennium? Proceedings of ICDE Conference, The New Learning Environment: A global perspective. Pennsylvania State University.

Hesketh, B., Gosper, M., Andrews, J. \& Sabaz, M. (1996).Computer-mediated communication in university teaching. Canberra: Australian Government Publishing Service.

Holmberg, B. (1989). Theory and practice of distance education. London: Routledge.

Jevons, F. (1986). Dual mode institutions - the way forward. Open campus n12, Deakin University: Geelong. 
Goodwin, C., Rice, M., Stacey, E. \& Thompson, L. (1995). An evaluation of Deakin Interchange pilot program. Deakin University: Geelong.

Karmel, P. (1975). Open tertiary education in Australia. Report of the Committee on the Future of Tertiary Education Australia to the Australian Universities Commission. Canberra: Commonwealth Government Printer.

Rowlands, J. (1997). Deakin's flexible teaching and learning initiatives. Paper presented to the Academic Development and Support Committee, Deakin University.

Stacey, E. (1997a). Collaborative Learning at a Distance. In Evans, T., Jakupec, V., \& Thompson, D. (Eds.), Research in Distance Education 4 Geelong: Deakin University Press.

Stacey, E. (1997b). A virtual campus: the experiences of postgraduate students studying through electronic communication and resource access. http://ultibase.rmit.edu.au/Articles/stace1.html

An acknowledgement to those at Deakin who contributed their time and ideas to the preparation of this paper: Professor Jocelyn Calvert, Dr Trevor Hutchins, Mr Ray Bantow, Ms Heather Briggs, Ms Anne Ingram.

\section{BIOGRAPHY}

Elizabeth Stacey is a lecturer in the Education Faculty at Deakin University in Melbourne Australia. She teaches educational computing courses particularly those incorporating the use of computers and communication technologies into curriculum. Her research and publications are focused on these areas. She has researched and published about school age learning with computers, and the use of interactive technologies, particularly audiographics and computer conferencing. Her doctoral research has explored collaborative group learning through computer mediated communication with adult learners.

She is currently coordinating the Master of Distance Education Course while teaching units about flexible teaching and learning which explore the integration of new technologies and supervising students studying student support issues which focus on this area. She is also part of the Education Doctorate team and is supervising students who are exploring flexible learning and the use of communication technologies in a range of settings. 